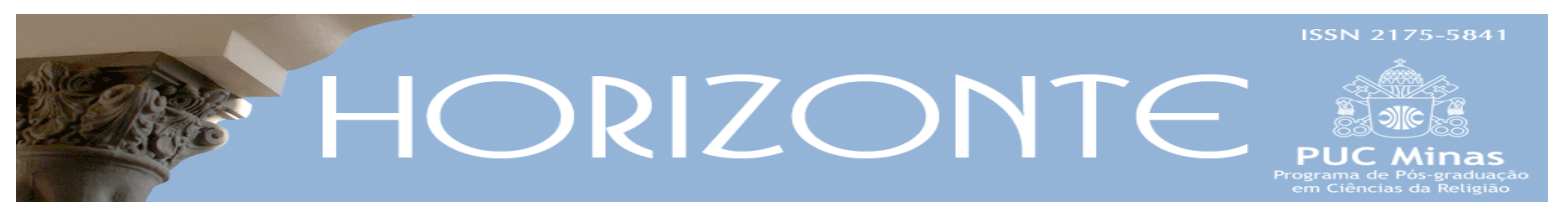

Dossiê: Religião, Direitos Humanos e Direitos da Natureza - Artigo Original (c) $($ i)

\title{
Las otredades de los pueblos indígenas de Abia Yala: una aproximación desde una perspectiva hermenéutica europea-intercultural
}

\author{
Indigenous peoples in Abia Yala and their forms of otherness: \\ approaches from an european-intercultural hermeneutic perspective
}

Elisabeth Steffens*

\begin{abstract}
Resumen
¿Los pueblos indígenas de Abia Yala - América Latina se puede comprender de otra manera en nuestros tiempos? Para ofrecer una respuesta a esta pregunta se describe un proceso de comprensión basado en una aproximación intercultural a sus otredades políticas y religiosas. Se examina primero como intelectuales no-indígenas han comprendido a los pueblos indígenas desde 1492. Por el escuchar cómo las y los indígenas se autoentienden se evidencia después lo que significa concretamente la lucha por el reconocimiento de los derechos indígenas y de la naturaleza en México, Ecuador y Bolivia. Luego se tematiza las teologías indígenas como motor del reconocimiento de las religiones indígenas. Se llega a la conclusión de que hay que superar por otros encuentros el malentendido de que todos los indígenas son seres humanos comunitarios que piensan y actuan de una manera cíclica mientras todos los seres humanos europeos son individualistas que piensan y actuan de una manera lineal.
\end{abstract}

Palabras claves: movimientos indígenas, filosofías indígenas, religiones indígenas y teologías indígenas, filosofía intercultural

\begin{abstract}
Can indigenous peoples in Abia Yala - Latin America in our time be understood in a different way? To give an answer to this question a process of understanding based on an intercultural approach to their political and religious otherness is described. First it is examined how non-indigenous intelectuals understood the indigenous peoples since 1492. By listening how indigenous women and men understand themselves it becomes evident then what the struggle for recognition of the indigenous rights and nature's rights mean concretely in Mexico, Ecuador and Bolivia. After that indigenous theologies are discussed as an egine for the recognition of indigenous religions. The article concludes that the misunderstanding that all indigenous are communitarians who think and act in a cyclical way while all europeans are indivualists who think and act in a linear way has to be overcome by other encounters.
\end{abstract}

Keywords: indigenous movements, indigenous philosofies, indigenous religions and indigenous theologies, intercultural philosofy

Artículo recibido el 21 de agosto de 2017 y aprobado el 23 de Septiembre de 2017.

* Doctora en Filosofía en la Universidad de Bremen, Alemania, en 2013, diplomada en Sciencias Regionales de América Latina en la Universidad de Colonia, Alemania, en 1996. Desde 2015 hasta 2017 estudiante de post-doctorado en cooperación con la Universidad de Quintana Roo, Chetumal, México. Docente en el Instituto de teología católica de la Universidad de Aachen; asistente scientífica en missio. País de Origem: Alemanha. E-mail: elsteffens@yahoo.com

Horizonte, Belo Horizonte, v. 15, n. 47, p. 719-735, jul./set. 2017 - ISSN 2175-5841 


\section{Introducción}

Abia Yala es una palabra milenaria kuna y significa tierra sangrante y fructífera. Durante el (re)surgimiento de las organisaciones indígenas en los años noventa del siglo pasado en América Latina sus protagonistas utilizan este termino Abia Yala para construir unidad en su lucha contra una política colonial explotadora y por el reconocimiento de sus derechos a la autodeterminacióno o se puede decir también de otra manera: a vivir sus culturas y religiones. Mostraron que el continente es desde su primer poblabiemto en la última época de glación pluricultural y plurireligioso (PAGANO FERNÁNDEZ, 1998, p. 14-16; STEFFENS, 2014, p. 43). ${ }^{1}$

Según un estudio de la CEPAL existen hoy más de "800 pueblos indígenas con una población cercana a los 45 millones" en Abia Yala (CEPAL 6). Desde 1492 no ceden los intentos desde Europa y de la población mestiza de homogenizar y erradicar a estos seres humanos. Para criticar estas actitudes propongo de repensar nuestra relación hacia estas culturas que muestran una gran diversidad y muchas otredades. Sus pueblos tienen muchos nombres: Mapuche, Guaraní, Quichua, Aymara, Kuna, Lenca, Ngäbe, Maya ...

Aproximarse a estas otredades culturales puede llevarse a cabo por medio de un proceso de comprensión. El comienzo de este proceso está marcado por una actitud de solidarización con estos pueblos que se entienden como sacrificios de la historia de Abia Yala. Esta solidarización nace de las experiencias de destrucción que estos seres humanos sufren desde el así llamado descubrimiento del continente en 1492. Según este estudio de la CEPAL en la época de los primeros contactos con europeos vivían “47 millones” de seres humanos indígenas en paises hoy llamados como latinoamericanos. "Sin embargo, se estima que 130 años después esta población había disminuido en un 90 \% y que la población indígena del Caribe casi

\footnotetext{
${ }^{1}$ Este artículo se basa en resultados básicos de este estudio con su bibliografía. Agradezco mucho a Celia Cabrera por haber revisado el texto.
} 
fue exterminada en menos de medio siglo" (CEPAL, 2014, p. 13). Sufrieron y siguen sufriendo hasta hoy día p.e. por la globalización neoliberal. Los sufrimientos se expresan en sus declaraciones y discursos. Indígenas critican, por ejemplo, los planes de festejo del quinto centenario en 1992 y exigen el reconocimiento de sus otredades. Escuchemos como los participantes se expresan en el III Encuentro continental de la campaña 500 años de resistencia indígena, negra y popular en Managua, Nicaragua, 7-12 de octubre de 1992: "Cargamos sobre nuestras espaldas los fardos de una deuda creciente, que no es más que nuestra riquzea convertida en préstamo. Como antes, de nuestras venas sale el oro; de nuestras entrañas, el petróleo; de nuestro sudor, los capitales; de nuestros sueños, las pesadillas de la represión y el hambre" (GIRARDI, 2001, p. 129-130).

Al escuchar esta descripción de la vida de muchos indígenas hoy, y al saber de su situación real hay que preguntarse por qué la situación de los indígenas no ha cambiado mucho apartir de 1492 (CONSEJERÍA DE DERECHOS DE LOS PUEBLOS INDÍGENAS, 2015; SERVINDI, 2015b; LÓPEZ BÁRCENAS, 2015; FIDH, CEDHU \& INREDH, 2015). Se puede encontrar una respuesta en la manera como los intelectuales no-indígenas han comprendido a los indígenas durante la historia.

\section{1 ¿Cómo han comprendido los intelectuales no-indígenas a los indígenas apartir de 1492 ?}

En los encuentros con seres humanos indígenas la pregunta por la razón es fundamental. En lo que se refiere a las crueldades de los españoles el padre dominicano Bartolomé de las Casas (1484-1566) piensa que los indígenas muchas veces tienen más razón que sus compatriotas. Pero no reconoce su otredad religiosa, hay que bautizarlo(a)s, tienen que ser cristiana(o)s. El jurísta de la corte española Juan Ginés de Sepúlveda (1490-1573), al contrario, les niega cualquiera forma de razón y por eso también su condición de seres humanos. 
Durante la época de la emancipación de la patria española para el presidente argentino Domingo Faustino Sarmiento (1811-1888) los indígenas son un obstáculo para el progreso. Por su racismo respecto a estos seres humanos quiere destruir la barbarie en el campo. Por eso hay que exterminarlos. Pero no logra convertir en americanos europeos a los indígenas salvajes, como por ejemplo los y las mapuches, que no han podido ser exterminados por su política.

El político y autor cubano José Martí (1853-1895) tiene una posición contraria a la de Domingo Faustino Sarmiento. Piensa en amar a los indígenas. Con ellas y ellos quiere construir "Nuestra América”, aunque hay que educar primero a estos indígenas (MARTÍ, 1974, p. 228-236). Por eso anima a un llegarse-a-conocer intra-culturalmente. Para él estos otros y estas otras indígenas son parte de la naturaleza y por eso la explotación de la naturaleza por medio de la cultura no es legítima.

$\mathrm{Al}$ analizar a los representantes de los movimientos indigenistas en el siglo veinte, surgen modelos de comprensión que son similares a los anteriores. Pero surgen también nuevos. Franz Tamayo (1879-1956), jurísta y político de Bolivia, está fascinado por la relación íntima de los indígenas con la tierra y sus costumbres. Por eso pide de los no-indígenas de andinizarse desde estas otras y estos otros. Su ojetivo es poner en marcha un sistema de formación propia, boliviana. Para José Carlos Mariátegui (1894-1930), marxista indigenista del Perú, la tierra es sólo un factor económico. Según él, los indígenas pueden llegar a un estado de bienestar luchando por sus derechos a la tierra. Su poder para llegar a este fin resulta de sus relaciones comunitarias vivas y su poder de resistencia por medio de fuentes mitológicas.

Se puede constatar que en México las políticas indígenistas tienen como meta final la destrucción de identidades indígenas y la explotación de su poder adquisitivo en favor de una política de progreso capitalista. La investigación sistemática de su diversidad cultural lleva al mismo tiempo a una reducción de 
inferioridades indígenas, a un reclamo por los derechos indígenas p.ej. a su tierra y a la construcción de la autoestima p.ej. por la organisación de congresos indígenas.

Este esbozo de encuentros históricos, directos e indirectos entre indígenas y no-indígenas muestran por qué este no-comprender y el no-reconcimiento de las otredades de los primeros pueblos de Abia Yala ha causado la muerte de miles de indígenas y la destrucción de sus culturas después de 1492. Las causas para esta no-comprensión son: No son cristianos, no tienen razón, no son seres humanos, son antiprogesistas, no son educados. Todos estos modelos de comprensión son ambivalentes, porque no sólo han llevado al no-reconocimiento respectivamente a la destrucción de culturas indígenas sino que, al mismo tiempo, muestran comienzos en dirección a un reconocimiento de las otredades indígenas. Las causas para este reconocimiento son: el amor, su actitud telurica-cultural, el poder de sus comunidades y de sus resistencias.

El análisis de métodos hermenéuticos, por ejemplo de Georg Wilhelm Friedrich Hegel (1770-1831) o de Hans Georg Gadamer (1900-2002), abre otra pista para comprender los causas de este no-reconocimiento. Según Hegel, los primeros pueblos de Abia Yala son pueblos sin historia, sólo la razón del occidente es la única vigente. (DÍAZ GENIS, 2004, p. 32) Según Gadamer, el fin del entendimiento es la fusión de horizontes: hay concordia al comienzo y al final de la conversación y la persona interpretante tiene el monopolio de definir la verdad. (BETTI, 1962, p. 39-46) Estas maneras de pensar han contribuido también a la extinción de la alteridad cultural o, dicho más concretamente, a la muerte de los muchos seres humanos indígenas.

Surge la pregunta si es posible otra manera de comprender a estos seres humanos en nuestros tiempos. 


\section{Hacia una actitud intercultural del escuchar}

El filósofo intercultural Raúl Fornet-Betancourt $\left({ }^{*} 1946\right)$ escucha a los y las indígenas y responde a sus críticas al colonialismo dominante vigente hoy. ${ }^{2}$ Escribe que los pueblos tienen el derecho "[...] no solamente a decir que ven el mundo de forma distinta, sino también, y sobre todo, a hacerlo según su propia manera de vivir [...]" (FORNET-BETANCOURT, 2001, p. 271). Su hermeneútica implica una práctica de reconocimiento de estos seres humanos porque tienen derechos a vivir sus culturas. Para realizar esta hermenéutica no sale de una teoría sino de una actitud que está dispuesta a dejarse cambiar apartir de las otras y los otros para renovar la filosofía y posibilitar la existencia armónica de mundos diferentes. Tal vez esta perspectiva intercultural abre la posibilidad de descolonizar estos métodos hermenéuticos eurocéntricos de Hegel y de Gadamer. Para alcanzar este fin necesitamos una cierta actitud. Hay por lo menos dos exigencias que deben ser realizadas para alcanzar tal actitud:

- Primera exigencia: Después de más que quinientos años de represión y sufrimiento es recomendable relacionarse a estos seres humanos primero guardando silencio y callándose.

Se podría describir tal actitud como una autolimitación ascética. Callar y escuchar sirve para la propia descolonización. Porque tal actitud da a la otra y al otro la posibilidad de decir como él o ella está. Esta posibilidad favorece la autoafirmación y la autoestima de la otra y el otro.

- Segunda exigencia: Con una actitud de callar y escuchar las relaciones hacia las otras y los otros se pueden construir de otra manera. Para realizar este fin no hay que suponer, como los filósofos Emanuel Levinas (19061995) y Enrique Dussel $\left({ }^{*} 1934\right)$ lo hicieron, que los indígenas son totalmente y radicalmente diferente de nosotras y nosotros. Si son

\footnotetext{
2 Juan Alfredo Blanco Galvez salió de un método intercultural-decolonial para aproximarse a la filosofía maya contemporáneo en Guatemala. (BLANCO GALVEZ, 2016)
} 
comprendidos absolutamente diferente de nosotros y nosotras, son negadas hacia afuera, porque no se les reconoce como parte de la persona que está en relación con los indígenas.

Por eso en referencia a Andrea Díaz Genis (*1968), hay que salir desde una actitud que entiende a estos seres humanos como reales $y$ relacionales respecto a nosotros y nosotras. Las otras y los otros no son a-históricos y a-históricas, no son los otros absolutamente diferentes de nosotros y nosotras, sino están en mi persona, en mí. Una persona nace a ser por la existencia de los otros y las otras, igualmente los otras y las otros nacen por mí. Ninguna persona es un ser sin relaciones, en todos los seres humanos se encuentra la materia de todas y todos (STEFFENS, 2014, p. 35).

En base de estas dos exigencias hacía una actitud intercultural del escuchar intento esbozar ahora una vía diferente de comprender a los indígenas de Abia Yala en nuestros tiempos. Escuchemos entonces cómo ellas y ellos se autoentienden y cómo este autoentendimiento caracteriza los levantamientos indígenas en la segunda mitad del siglo pasado.

\section{3 ¿Cómo los y las indígenas se autoentienden?}

La autoconciencia de los representantes del movimiento indianista nos otorga una pista para responder a esta pregunta. Los indianismos que surgen en los años setenta del siglo pasado se entienden como movimientos contra las enajenaciones indigenistas y las destrucciones descritas. Son el fundamento de los levantamientos que llegan a su punto culminante en el seno del quinto centenario en los años 80 y 90. Llamo a su filosofía "filosofía del resurgimiento" porque su modo de pensar ha marcado el levantamiento indígena continental en el contexto de este vuelco histórico.

Empiezo con la presentación del famoso intelectual quechua de Bolivia: Fausto Reinaga (1906-1994), representante del movimiento indianista. Durante su 
vida su identidad recibe diferentes características: $\mathrm{Su}$ ser quechua recibe una caracteríctica cristiana-mestiza durante su tiempo escolar. Después de sus estudios de derecho llega a ser marxista como catedrático de filosofía. Después de sus actividades en favor de los pueblos indígenas en su pais llega a conocer la situación real de la población en Rusia. Esta experiencia provoca una ruptura con el marxismo y una reafirmación de su identidad quechua. Esto son momentos claves en su vida.

$\mathrm{Al}$ aproximarse a su obra se pueden constatar algunas características de la filosofía del resurgimiento de Fausto Reinaga. Niega el mundo occidental totalmente, reafirma su cultura nativa, idealiza la historia de Abia Yala antes de 1492 e intenta construir la unidad entre los primeros pueblos y un diálogo con las otras culturas. Para él, la indianidad es el espacio cósmico de todos los seres humanos que quieren liberarse de la prisión hispana, helenísta-cristiana y marxista. La indianidad es para él un camino propio para levantar en Bolivia una nación real desde los quechua y aymara. Se necesita sobre todo tierra para realizar este proyecto. Como para él todo es circular: el sol, la luna, la matriz y el tiempo, habla de una razón cósmica-vital en el mundo nuevo. En el occidente impera unicamente una razón lineal, que procova individualismo, egoismo, el robar y un culto al progreso científico. En el fondo eleva a las y los indígenas a civilizados y civilizadas y rebaja las europeas y los europeos a bárbaros y bárbaras.

Después de haber presentado a Fausto Reinaga como representante del indianismo nos dedicamos ahora a los indianismos en organizaciones indígenas. Llamo a su filosofía también "filosofía del resurgimiento". El motivo por el cual se fundaron muchas organizaciones indígenas sobre todo en los años setenta del siglo pasado en Colombia (p.e. CRIC), Bolivia (MINK'A), Ecuador (ECUARUNARI) en nivel local, sobreregional, nacional y supranacional se basa en la defensa de su territorio y su autonomia política en las regiones en las que viven. Los elementos de su filosofía del resurgimiento nos hacen pensar en Fausto Reinaga. Lo que llama la atención es que los y las indianistas en Bolivia se autodefinen como indios pero 
también como campesinos. Por una parte, se identifican con la identidad india y, por otro lado, quieren liberarse de ella. Junto con otros grupos como los trabajadores en las minas y fábricas, los empleados en el sector del transporte quieren renovar el país pluriculturalmente. Para un grupo intelectual de indianistas la célula cultural de estos resurgimientos es por lo menos teóricamente la unidad complementaria entre mujer y hombre. Tiene su origen en el cosmos y sus relaciones horizontales que son la base de sus organisaciones jerárquicas. Para un grupo de indianistas en Colombia la vuelta hacia la cultura propia nace desde la tierra. Para este grupo la tierra no es sólo objeto de su trabajo, sino también origen y centro de la vida.

En la crítica de los y las indianistas respecto a los planes eurocéntricos de festejar el quinto centenario se puede observar una estrategia fundamental: polarizan el mundo occidental individualista-lineal y el mundo indígena comunitario-circular. Condenan la explotación ejercida por los gobiernos, las empresas transnacionales y las iglesias. Quieren provocar, así, la vuelta de la historia colonial. Por eso surge un cambio histórico que no implica sólo el reconocimiento de su otredades, sino también el buen vivir para todos y todas - o dicho de otro modo - la nueva creación de Abia Yala con los otros grupos de los paises respectivos.

\section{4 ¿Qué significa el reconocimiento de las otredades indígenas en concreto?}

En principio se puede responder a esta pregunta que el reconocimiento de las otredades indígenas implica una nueva creación pluriculutral de Abia Yala. Se trata de abrir las estructuras monoculturales y antropocéntricas respectivamente androcéntricas. Esto implica la construcción de estados plurinacionales y plurireligiosos (KLITZKE ROZAS, 2015; SERVINDI, 2015a).

Respecto a lo plurinacional esto significa: A través de las reformas constitucionales en Ecuador (2008) y en Bolivia (2009) se realiza esta urgencia por 
lo menos teóricamente, porque por ellas los pueblos indígenas como también los otros seres de la naturaleza reciben el estatus de sujetos, de sujetos jurídicos. Así según sus filosofías holísticas la lucha por el reconocimiento de los derechos indígenas incluye también el reconocimiento de los derechos de la naturaleza, de la Madre Tierra.

Al aproximarse a movimientos de resurgimiento en México, Ecuador, Bolivia, Guatemala y Perú se manifiesta que no basta hablar de el reconocimiento de las otredades indígenas. La práctica del reconocimiento tiene muchas facetas que están enlazadas. Se trata de un autoreconocimiento y un reconocimiento intracultural, intercultural y internacional. Esbozo lo que significa este reconocimiento con sus muchas facetas en concreto:

Durante el levantamiento zapatista en Chiapas, México, en 1994 el autoreconocimiento de las luchadoras zapatistas tiene un rol importante. Por medio de la ley revolucionaria de mujeres aprobado en 1993 las mujeres obligan a los hombres zapatistas a reconocerlas como co-luchadoras con los mismos derechos y deberes. Así, comenta la ley Susana, una mujer maya-tzotzil: "Queremos que no nos obliguen a casarnos con el que no queremos. Queremos tener los hijos que queramos y podamos cuidar. Queremos derecho a tener cargo en la comunidad. Queremos derecho a decir nuestra palabra y que se respete. Queremos derecho a estudiar y hasta de ser choferes" (SUBCOMANDANTE MARCOS, 1994).

En el Ecuador la lucha por el reconocimiento significa el llegar-a-conocer a las otredadas intra-culturales. Esto quiere decir que representantes del pueblo Quichua y del pueblo Cofán se dicen primero cómo son. Así lo ha descrito también José Martí: se dicen primero, como son. Para Bolivia el reconocimiento intracultural significa incluso la reducción de discriminaciones entre los indígenas del altiplano y de las tierras bajas.

Partiendo del hecho de que los primeros pueblos existieron antes de la llegada de los europeos con sus propias sistemas culturales implica el 
reconocimiento intercultural de la construcción de un estado plurinacional en el Ecuador. Significa: la nueva distribución del pais correspondiendo a los territorios de los pueblos, el reconocimiento de los gobiernos locales existientes y la participación de los pueblos y nacionalidades indígenas en nivel nacional.

El núcleo para el reconocimiento internacional de las culturas indígenas y la nueva construcción pluricultural de los paises de Abia Yala es el derecho a la consulta previa, libre e informada. Está reconocido en el Convenio de la Organisación Internacional del Trabajo (OIT, 2014) número 169 (artículo 15, apartado 2) y en la Declaración de las Naciones Unidas sobre los derechos indígenas (Artículo 32, apartado 2) a nivel internacional (OIT, 2014, art. 37-38; NACIONES UNIDAS, 2008, p. 12). También la Constitución de la República del Bolivia (artículo 30, apartado 15) reconoce el derecho a la consulta previa de las y los indígenas (ASAMBLEA CONSTITUYENTE DE BOLIVIA, 2008). Las consultas significan para los pueblos una práctica milenaria para arreglar cuestiones de la comunidad, de la familia y de la persona de una manera dinámica. Escuchemos como lo definen organisaciones indígenas del Perú:

Es el derecho de los pueblos indígenas a que la adopción de medidas administrativas o legislativas susceptibles de afectarlos directamente, sea antecedida de un proceso de diálogo entre sus instituciones representativas y el Estado. El proceso de consulta es la obligación del Estado por la cual se garantiza la participación de los pueblos indígenas en sus decisiones y tiene por finalidad llegar a un acuerdo o consentimiento sobre las medidas administrativas o legislativas propuestas, en el marco de un diálogo intercultural de buena fe, basado en la generación de relaciones que propicien la equidad y el respeto. El derecho de consulta no otorga a las poblaciones derecho a veto (SEVILLANO ARÉVALO, 2010, p. $65)$.

El estado guatemalteco viola este derecho reconocido a nivel internacional continuamente para permitir a las empresas internacionales p.e. la explotación de la fuerza hidráulica, aunque ha ratificado el convenio 169 de la OIT en 1996.

Las comunidades indígenas reaccionan a este no-reconocimiento de sus derechos y a la corrupción en los niveles políticos y empresariales en Guatemala y en el Perú con autoconsultas. Este derecho a la consulta histórica recibe así el 
caracter de un derecho a la resistencia contra la destrucción de sus territorios, las criminalizaciones ilegales de las y los indígenas, y su derecho a proponer otros modelos de desarrollo. El derecho a la consulta tiene el fin de revertir la historia de marginación y explotación para construir relaciones justas y para aportar a una decolonización (CEPAL, 2014, p. 28; CAMPANARIO BAQUÉ \& GARCIA HIERRO, 2016).

En el fondo se trata de un derecho a una construcción oficial de un Abia Yala plurinacional que no se puede separar de lo plurireligioso. La importancia de la religion maya en Guatemala y la relación entre indígenas y cristianos ofrecen una pista para demostrar la validez de esta tesis.

La guerra cívil que comienza en los años sesenta del siglo pasado en Guatemala no destruye sólo los fundamentos de la cultura maya sino de su religión. En medio de esta represión brutal representantes mayas redescubren su cosmovisión. Este redescubrimiento caracteriza también la irrupción del movimiento maya en los años 90, porque en diferentes organizaciones mayas se celebran ritos respecto al calendario maya. También en el Comisionado para Asuntos Indígenas y Sitios Ceremoniales se celebran ritos, por ejemplo en 2005 para pedir permiso a la madre tierra para explorar su intererior o mejor dicho para sacar recursos (BASTOS; CUMES, 2007, p. 70). Esta instrumentalización de los ritos es muy dudosa y contradictoria.

En general, se puede decir respecto a la alteridad religiosa que en grupos católicos domina la opinión de que la mayoría de los y las indígenas son cristianos y cristianas. Por eso los indigenas exigen, por ejemplo, a los obispos que se encuentran en la conferencia episcopal en Santo Domingo en 1992 no sólo reconocer sus culturas sino también a sus religiones. Los indígenas escriben a los obispos allí reunidos: "Cuando se refieran a nuestros pueblos no opten Ustedes sólo por el pobre, sino de igual medida por el 'otro, culturalmente distinto', sobre la base del reconocimiento de nuestras religiones nativas, aún vivas y pujantes; reconocimiento de nuestras maneras de vivir la fe, de nuestras culturas, de 
nuestras tierras, de nuestras autonomías. No sólo se trata de culturas muy religiosas, sino de verdaderas religiones” (WAGUA, 1998, p. 342).

Dentro de este escenario se fundamenta el moviemiento de las teologías indígenas que llega a ser también una voz crítica contra la globalización neoliberal. Una característica básica de sus representantes es su identidad doble, que se compone de su fe indígena y cristiana. Por medio de los encuentros continentales de este movimiento, el autoreconocimiento indígena, sobre todo de la mujer, recibe un fuerte impulso. Ellas sufren por las contradicciones de las religiones cristianas al igual que de las religiones indígenas y durante el VI encuentro de las teologías indígenas en El Salvador en 2009 fundan la primera comunidad de las teológas indígenas de Abia Yala (ALC, 2010).

Resumiendo, se puede decir que la práctica del reconocimiento de las otredades indígenas en Abia Yala necesita más relaciones horizontales entre indígenas y no indígenas. En concreto, pienso en diálogos interreligiosos entre guías espirituales, teológas y teológos indígenas y no indígenas. Pero estos diálogos entre iguales no son suficientes. Porque además estas relaciones hay que interculturalizarlas. De parte de las diferentes iglesias cristianas en Europa no hay mucha disposición a reconocer oficialmente el encuentro con los indígenas no cristianos como enriquecimiento recíproco. Faltan cambios estructurales importantes como el reconocimiento de diáconos en parejas por parte del Vaticano aunque el Papa Francisco ha cancelado la prohibición de diáconos en Chipas en 2014 después de 14 años (HENRÍQUEZ, 2014, p. 24).

En general, el Papa Francisco ha reconocido que los diálogos interreligiosos pueden aportar al enriquecimiento mutuo. ¿Pero ha propuesto una iniciativa concreta hacia un reconocimiento de las religiones indígenas? ¿Porqué no inicia un diálogo oficial con los indígenas no cristianos y cristianos comenzando con las siguientes preguntas de la declaración "Nostra Aetate" del Concilio Ecuménico Vaticano Segundo?: 
¿Qué es el hombre, cuál es el sentido y el fin de nuestra vida, el bien y el pecado, el origen y el fin del dolor, el camino para conseguir la verdadera felicidad, la muerte, el juicio, la sanción después de la muerte? ¿Cuál es, finalmente, aquel último e inefable misterio que envuelve nuestra existencia, del cual procedemos y hacia donde nos dirigimos? (PAULO VI, 1965, n. 1).

\section{Perspectivas e consideraciones finales}

$\mathrm{Al}$ principio de esta aproximación a las otredades de los pueblos indígenas de Abia Yala la actitud respecto a ellos y ellas fue descrita como solidaria. Durante este proceso de entendimiento ella es complementada por un cuestionamiento crítico de los modos de vivir y de pensar europeos y indígenas. Así tuvo lugar un desplazamiento: Al final de este proceso están cara a cara seres humanos indígenas de Abia Yala y seres humanos de Europa. Desde una perspectiva indígena, los indígenas son seres humanos comunitarios que piensan y actuan de una manera cíclica mientras los seres humanos europeos son individualistas que piensan y actuan de una manera lineal.

Pero las dos preguntas finales muestran que estos dos polos pueden ser abandonados y superados:

Primero: ¿El anhelo indígena hacía un mundo donde quepan todos y todas y hacía una tierra sin males no es expresión de un pensar lineal?

Y segundo: ¿Qué es el individualismo que caracteriza a los europeos y las europeas cuando en el fondo todo lo que vive siempre está en relación con los otros seres humanos y no humanos?

Con estas preguntas al final no quiero disolver el ajeno indígena en lo propio europeo ni disolver lo propio europeo en lo ajeno indígena. Los indígenas piensan y actuan también de forma lineal y los europeos son individualistas desde una perspectiva no-cósmica. Espero que esta conclusión abra posibilidades para superar este malentendido y para crear otra base para el encuentro entre indígenas 
y europeo(a)s. Ella puede servir para la preparación de otros encuentros con indígenas y ser al mismo tiempo el comienzo de un cuestionamiento intracultural del pensar y actuar propios.

\section{REFERENCIAS}

ALC - Agencia Latinoamericana y Caribeña de Comunicación. El Salvador: Primera comunidad de teólogas indígenas. 2010. Disponible en:

$<$ http://www.redescristianas.net/el-salvador-primera-comunidad-de-teologasindigenas/>. Consulta en: 13 julio 2016.

ASAMBLEA CONSTITUYENTE DE BOLIVIA. Nueva Constitución Política del

Estado, 2008. Disponible en:

<http://pdba.georgetown.edu/Constitutions/Bolivia/constitucion2009.pdf $>$. Consulta en: 13 julio 2016.

BASTOS, Santiago; CUMES, Aura (Ed.). Mayanización y vida cotidiana. La ideología multicultural en la sociedad guatemalteca. Ttomo 1. Guatemala: Centro de Formación Agencia Espanõla de Cooperación Intenacional, 2007.

BETTI, Emilio. Die Hermeneutik als allgemeine Methodik der

Geisteswissenschaften. Tübingen: Mohr (Siebeck), 1962.

BLANCO GALVEZ, Juan Alfredo. Sobre el pensar intercultural-decolonial. El proyecto intercultural-decolonial del pensamiento maya contemporáneo en Guatemala. Concordia. Serie Monografías, tomo 66. Aachen: Verlag Mainz, 2016.

CAMPANARIO BAQUÉ, Yaizha; GARCIA HIERRO, Pedro. Empresas domiciliadas en países ratificantes del convenio 169-OIT operando en territorios de pueblos indígenas en Perú. El caso de la empresa española Repsol. Disponible en:

<http://codpi.org/images/stories/materiales/libros/Caso\%2oRepsol\%2oPeru/PeruRepsol _versionweb.pdf>. Consulta en: 13 julio 2016.

CEPAL. Síntesis. Los pueblos indígenas en América Latina. Avances en el último decenio y retos pendientes para la garantía de sus derechos. Santiago de Chile: CEPAL, 2014.

CONSEJERÍA DE DERECHOS DE LOS PUEBLOS INDÍGENAS. Informe 2015 sobre vulneraciones a los DDHH e Infracciones al DIH. 2015. Disponible en: <https://issuu.com/connpueblos/docs/resumen_informe_vulneraciones_ddhh>. Consulta en: 14 julio 2016.

DÍAZ GENIS, Andrea. La construcción de la identidad en América Latina. Una aproximación hermenéutica. Montevideo: Nordan Comunidad, 2004. 
FIDH, CEDHU \& INREDH. Ecuador: Criminalización de la protesta social frente a proyectos extractivos en Ecuador. Misión Internacional de Investigación, no. 666e. 2015. Disponible en: <https://www.fidh.org/IMG/pdf/equateur666espagn2015hd_1_.pdf>. Consulta en: 8 julio 2016.

FORNET-BETANCOURT, Raúl. Transformación intercultural de la filosofía. Bilbao: Palimpsesto, 2001.

FRANCISCO. El papa defiende el diálogo interreligioso en 'la convivencia respetuosa' y no en el pensamiento 'neutral'. 6 Diciembre 2013. Disponible en: <https://dialogointerreligioso.wordpress.com/tag/francisco-i/>. Consulta en: 14 julio 2016.

GIRARDI, Giulio. Los excluídos. Madrid: Editorial Nueva Utopía, 2001.

HENRÍQUEZ, Elio. Arizmendi: Roma autorizó ordenar más diáconos permanentes. 25 Mayo 2014. Disponible en: <http://www.jornada.unam.mx/2014/o5/25/estados/o24n4est>. Consulta en: 13 julio 2016.

KLITZKE ROZAS, Barbara. Indigene in Guatemala für Gründung eines Plurinationalen Staates. 3 Diciembre 2015. Disponible en: <https://amerika21.de/2015/11/136905/indigene-voelker-guatemala >. Consulta en: 8 julio 2016.

LÓPEZ BÁRCENAS, Francisco. La nueva guerra contra los pueblos indígenas. 24 julio 2015. Disponible en:

<http://www.jornada.unam.mx/2015/o7/24/opinion/o17a2pol>. Consulta en: 8 julio 2016.

MARTÍ, José . Nuestra América. In: RIPOLL, Carlos (Ed.). Conciencia Intelectual de América. New York: Eliseo Torres, 1974.

NACIONES UNIDAS. Declaración de las Naciones Unidas sobre los derechos de los pueblos indígenas, Naciones Unidas, 2008. Disponible en:

<http://www.un.org/esa/socdev/unpfii/documents/DRIPS_es.pdf >. Consulta en: 13 julio 2016.

ORGANIZACIÓN INTERNACIONAL DEL TRABAJO. Convenio Núm. 169 de la OIT sobre pueblos indígenas y tribales en países independientes. Declaración de las Naciones Unidas sobre los Derechos de los Pueblos Indígenas, Lima OIT/Oficina Regional para América Latina y el Caribe, 2014.

PAGANO FERNÁNDEZ, Carlos María. Abia Yala: Liberación de América. Abia Yala, San José, v. 4, n. 3, p. 14-16, 1998. 
PAULO VI. Declaración Nostra Aetate. Sobre las relaciones de la iglesia con las religiones no cristianas. 28 Octubre 1965. Disponible en:

<http://www.vatican.va/archive/hist_councils/ii_vatican_council/documents/vatii_decl_19651028_nostra-aetate_sp.html>.Consulta en: 17 Agosto 2015.

SERVINDI. México: Indígenas llaman a la unidad para refundar el Estado. 18 julio 2015 . Disponible en: <http://servindi.org/actualidad/135477\#more-135477>. Consulta en: 8 julio 2016.

SERVINDI. Brasil: ¿Quién detiene la violencia contra indígenas en Mato Grosso do Sul?. 30 Agosto 2015b. Disponible en:

<http://servindi.org/actualidad/138547?utm_source=feedburner\&utm_medium=email\& utm_campaign=Feed\%3A+Servindi+\%28Servicio+de+Informaci\%C3\%B3n+Indigena\%29 >. Consulta en: 8 julio 2016.

SEVILlanO ARÉVALO, M. Informe. El derecho a la Consulta de los Pueblos Indígenas en el Perú - Últimos Avances. 2010, p. 65. Disponible en:

<http://www.elaw.org/system/files/El+Derecho+A+La+Consulta+De+Los+Pueblos+Indi genas+En+El+Peru.pdf $>$. Consulta en: 8 julio 2016 .

STEFFENS, Elisabeth. Politische und religiöse Alterität als hermeneutische Herausforderung: Die indianischen Völker Abia Yalas, Denktraditionen im Dialog: Studien zur Befreiung und Interkulturalität, tomo 73, Aachen: Wissenschaftsverlag Mainz, 2014 .

SUBCOMANDANTE MARCOS. Ley Revolucionaria de mujeres zapatistas. Fragmento de la Carta de Marcos sobre la vida cotidiana en el EZLN del 26 de enero de 1994. Disponible en: <https://mujeresylasextaorg.wordpress.com/ley-revolucionaria-demujeres-zapatistas/>. Consulta en: 13 julio 2016.

WAGUA, Aiban. Presupuestos para una inculturación del evangelio en el mundo indígena. Misiones Extranjeras, Medellin, n. 165, p. 342, 1998. 